\title{
INFLUÊNCIA DE DIFERENTES NÍVEIS DE SOMBREAMENTO SOBRE O CRESCIMENTO DE MUDAS DE CAFEEIRO (Coffea arabica L.)
}

\author{
LEANDRO CARLOS PAIVA ${ }^{1}$ \\ RUBENS JOSÉ GUIMARÃES ${ }^{2}$ \\ CARLOS ALBERTO SPAGGIARI SOUZA ${ }^{2}$
}

\begin{abstract}
RESUMO - Com o presente trabalho objetivou-se determinar o melhor processo de formação de mudas em diferentes níveis de sombreamento. $\mathrm{O}$ experimento foi conduzido no Setor de Cafeicultura do Departamento de Agricultura da UFLA, onde mudas de cafeeiro (Coffea arabica L.)foram formadas sob quatro diferentes tipos de luminosidade, sendo: em pleno sol e sob sombrites, com $30 \%, 50 \%$ e $90 \%$ de sombreamento. Os tratamentos foram dispostos em um delineamento com blocos
\end{abstract}

casualisados, sendo quatro o número de blocos. O experimento foi conduzido até que as mudas atingissem o terceiro-quarto pares de folhas. As avaliações constituíram as seguintes análises de crescimento: altura, diâmetro de caule, número de pares de folha, peso seco de raíz, peso seco de parte aérea e área foliar. Concluiu-se que para as características de crescimento analisadas, as mudas sob sombrite com $50 \%$ de sombreamento foram melhores, seguidas daquelas com $90 \%, 30 \%$ e pleno sol.

TERMOS PARA INDEXAÇÃO: Café, mudas, pleno sol, crescimento, Coffea arabica.

\section{INFLUENCE OF DIFFERENT SHADING LEVELS ON THE GROWTH OF COFFEE SEEDLINGS (Coffea arabica L.)}

\begin{abstract}
The present work aimed to determine the best shading levels for the growth of coffee seedlings. The experiment was carried out at the Agriculture Department of the Federal University of Lavras. Coffee seedlings (Coffea arabica L.) were grown under four shading levels: seedlings in full sunshine, and under $30 \%, 50 \%$, and $90 \%$ shading. The treatments were arranged in a randomized
\end{abstract}

block design, whith four replications. The experiment was run to the third/fourth leaf pair. Afterwards, the following analyses were performed: height, stem diameter, number of leaf pairs, root dry weight, shoot dry weight, and leaf area. Results showed the seedlings develop best under $50 \%$ shading, then 90 and $30 \%$ shading, and lastly under full sunshine.

INDEX THERMS: Coffee, seedlings, full sunshine, growth, Coffea arabica.

\section{INTRODUÇÃO}

Os viveiros para café utilizados atualmente são construídos das mais variadas formas e materiais. Todos devem apresentar um padrão, como: os saquinhos são dispostos em canteiros planejados e para facilitar o manejo, as laterais do viveiro devem ser cercadas com material que deixe passar $50 \%$ de luz (bambu, ripado, sombrite, etc.), evitando insolação direta nas mudas; a cobertura pode ser alta (cerca de $1,8 \mathrm{~m}$ a $2,2 \mathrm{~m}$ ) ou baixa $(1,5 \mathrm{~m})$, deve ser perpendicular ao caminhamento do sol e pode ser feita dos mais variados materiais (bambu, ripado, sombrite, napier, etc.), sempre visando a manter o sombreamento em 50\%. Tais recomendações são utilizadas há muito tempo e se tornaram padrão para formação de mudas.

Apesar da tradição de formação de mudas com $50 \%$ de sombreamento, alguns produtores resolveram formar mudas a pleno sol, visando principalmente a melhorar a adaptação das plantas às condições de campo e economizar na estrutura para o viveiro. Porém, há uma certa dificuldade na manutenção com relação à umidade, sendo a irrigação, por sua vez, mais intensa nesse tipo de formação de mudas, o que restringe seu uso em propriedades onde a água é escassa.

1. Engenheiro Agrônomo, MS.

2. Professor, Dr. do Departamento de Agricultura da UNIVERSIDADE FEDERAL DE LAVRAS/UFLA, Caixa Postal 37 - 37200-000 - Lavras, MG. 
Sabe-se que o cafeeiro é uma planta $\mathrm{C}_{3}$, ou seja, é uma planta de ambiente sombreado, que possui adaptações fisiológicas e morfológicas para isso. Mas é também uma espécie que se adaptou bem às condições de pleno sol, justificando, assim, um estudo de seu crescimento na fase de muda. Tais adaptações morfológicas e fisiológicas das mudas formadas a pleno sol ainda são pouco estudadas e não se tem uma idéia formada sobre o processo e seus resultados.

A produção de mudas de cafeeiro a pleno sol já é uma técnica utilizada por alguns viveiristas e produtores. Seus resultados e utilizações são embasadas, na maioria das vezes, por observações, havendo a necessidade de trabalhos científicos que possam mostrar a real possibilidade de utilização do método.

Em dois viveiros de um milhão de mudas em cada um, produzidas nessa técnica, na região de Manhuaçu e Lajinha, na Zona da Mata mineira, as mudas tiveram valores de comprimento do sistema radicular, peso da parte aérea e peso do sistema radicular praticamente iguais e altura com tendência a ser superior, sendo a relação sistema radicular / parte aérea maior. Com esses resultados observados por Matiello et al., (1997), criouse uma grande expectativa para a produção de mudas a pleno sol.

Em mudas de guarea [Guarea guidonea (L.) Sleumer - Meliaceae], foi avaliado o desenvolvimento sob condições de viveiro, tendo sido testados três níveis de sombreamento (pleno sol, $30 \%$ e $50 \%$ ). Mediram-se altura, diâmetro do colo, peso da matéria seca total, folhas, caule e raiz, área foliar, relação raiz / parte aérea e quantificaram clorofilas "a", "b" e total. As análises foram realizadas aos 230 dias após a repicagem das plântulas, permitindo concluir que Guarea guidonea, na fase de muda, apresentou melhor desenvolvimento vegetativo com $50 \%$ de sombreamento. Com relação aos teores de clorofila, foram observadas tendências de queda com aumento progressivo da intensidade luminosa, fatos esses que sugerem sua maior aptidão para condições sombreadas na fase de viveiro.

$\mathrm{O}$ crescimento das plantas resulta de interações envolvendo carboidratos, hormônios, água e minerais. Embora a fotossíntese seja considerada o maior processo fisiológico do crescimento, por fornecer a matériaprima necessária (Kozlowski, 1962, citado por Engel, 1989), o desenvolvimento de uma planta envolve importantes mecanismos regulatórios de conversão e distribuição de assimilados.

A adaptação das plantas ao ambiente de luz depende do ajuste de seu aparelho fotossintético, de modo que a luminosidade ambiental seja utilizada de maneira mais eficiente possível. As respostas dessa adaptação serão refletidas no crescimento global da planta. Assim, a eficiência do crescimento pode estar relacionada com a habilidade de adaptação das plântulas e as condições de intensidade luminosa do ambiente; freqüentemente as análises do crescimento são utilizadas para predizer o grau de tolerância das diferentes espécies ao sombreamento, Engel (1989).

Várias características são utilizadas para avaliar as respostas de crescimento de plantas à intensidade luminosa. Entre essas, a altura da planta é uma das mais utilizadas, visto que a capacidade em crescer rapidamente em altura quando sombreadas é um mecanismo importante de adaptação das espécies que procuram por uma taxa luminosa maior, Engel (1989). Outro parâmetro bastante utilizado é o diâmetro do colo. O crescimento em diâmetro depende da atividade cambial que, por sua vez, é estimulada por carboidratos produzidos pela fotossíntese e hormônios translocados das regiões apicais. Logo, o diâmetro de colo é um bom indicador da assimilação líquida, já que depende mais diretamente da fotossíntese, (Kozlowski, 1962 citado por Engel, 1989). A exemplo, mudas de cacau obtiveram diâmetros maiores em intensidades de $50 \%$ e $70 \%$ de sombra (Murray \& Nichols, 1966, citados por Engel, 1989).

A produção de matéria seca permite avaliar o crescimento de uma planta. A quantidade total de matéria seca acumulada pela planta é reflexo direto da produção fotossintética líquida, somada à quantidade de nutrientes minerais absorvidos, o que corresponde apenas a uma pequena parcela daquela (Bourdeau, 1958, citado por Engel, 1989).

A área foliar é uma característica para se analisar a tolerância à sombra das diferentes espécies, pois ela correlaciona-se diretamente com a área da superfície fotossintetizante útil. $\mathrm{O}$ aumento da área foliar pelo sombreamento é uma das maneiras de a planta aumentar a superfície fotossintetizante, promovendo um aproveitamento maior das baixas intensidade luminosas, Engel (1989), compensando, assim, as taxas fotossintéticas por unidade de área mais baixas, que são características de folhas de sombra, Boardman (1977).

O maior crescimento da área foliar das mudas, verificado em $50 \%$ de sombreamento, está em consonância com o de outras espécies clímax, que também utilizam essa estratégia morfofisiológica para aumentar a eficiência de aproveitamento das baixas intensidades luminosas que chegam ao interior da planta ou do ecossistema (Ferreira, 1977; Engel, 1989).

Assim, o objetivo com o presente trabalho foi comparar o crescimento de mudas de cafeeiro, produ- 
zidas em diferentes níveis de sombreamento e a pleno sol.

\section{MATERIAL E MÉTODOS}

O experimento foi conduzido no período de setembro de 1999 a abril de 2001, no viveiro de produção de mudas do Setor de Cafeicultura do Departamento de Agricultura da Universidade Federal de Lavras (UFLA), no município de Lavras, localizado na região sul no Estado de Minas Gerais. O local do experimento está a uma altitude média de $918 \mathrm{~m}$ dentro da latitude $21^{\circ} 14^{\prime} \mathrm{S}$ e longitude $45^{\circ} 00^{\prime} \mathrm{W}$ GRW. As médias anuais de temperatura do ar, máxima e mínima, são respectivamente de $26,1^{\circ} \mathrm{C}$ e $14,4^{\circ} \mathrm{C}$, e a temperatura média anual é de $19,4^{\circ} \mathrm{C}$. A precipitação total anual é de $1529,7 \mathrm{~mm}$. O clima regional é do tipo Cwa, mas apresenta características de Cwb com duas estações distintas: seca (de abril a setembro) e chuvosa (de outubro a março), segundo a classificação de Köppen.

O viveiro onde foi instalado o experimento é do tipo cobertura alta e foi dividido em partes, nas quais foi colocado um tipo de cobertura, que compôs os tratamentos a seguir: área sem sombrite (Pleno Sol), sombrite de $30 \%$, sombrite de $50 \%$, sombrite de $90 \%$. Os canteiros foram dispostos no centro de cada área, cobertos de modo a não serem influenciados por outros tipos de sombreamento em nenhuma hora do dia.

As mudas foram formadas em saquinhos de polietileno perfurados, de cor preta, com as dimensões usuais para mudas de café $(11 \times 22 \mathrm{~cm})$. Depois de encanteirados, os saquinhos foram semeados com duas sementes de café da cultivar Rubi MG 1192. As sementes foram cobertas com areia lavada de rio e sacos de aniagem para manter a umidade durante a germinação. Depois de germinadas as sementes, foi deixada apenas uma planta por saquinho.

O substrato utilizado foi o padrão para mudas de café, constituído de 700 litros de terra de subsolo peneirada, 300 litros de esterco de curral curtido e peneirado, $5 \mathrm{~kg}$ de superfosfato simples e $0,5 \mathrm{~kg}$ de cloreto de potássio.

O delineamento experimental utilizado foi o de Blocos Casualizados, sendo 4 o número de repetições por tratamento. As parcelas constaram de 18 plantas, sendo 5 úteis.

Durante a condução do experimento, as regas foram feitas diariamente, de forma manual, mantendo sempre a capacidade de campo do substrato para todos os tratamentos. Isso significou um aumento, às vezes, de até duas regas para o tratamento a pleno sol, que perdia água mais rapidamente por evaporação.

Para avaliar o crescimento das plantas, as variáveis adotadas foram:

Altura das Plantas: medida de colo das plantas até a gema apical, em centímetros.

Diâmetro do caule: medida no colo da planta com um paquímetro, em milímetros.

Área foliar: medida em centímetros quadrados, estipulada pela fórmula:

$\mathrm{AF}=\{[($ comprimento $\mathrm{x}$ largura $) \times 0,667] \times 2\}$

Peso de matéria seca de raiz e parte aérea: após a lavagem com cuidado das raízes e da parte aérea, retirando toda a terra, secionou-se o caule na altura do colo. A parte aérea e as raízes foram acondicionadas em sacos de papel devidamente etiquetados com os números dos tratamentos. Posteriormente, as amostras foram secas em estufa de ar circulado, a $60^{\circ} \mathrm{C}$, até peso constante. Pesou-se o material em balança de precisão, com medida dada em gramas.

Número de pares de folhas: contagem direta do número de pares de folhas.

No caso de medidas de crescimento, dois subgrupos foram evidenciados: o primeiro constituindo medidas primárias, como altura, diâmetro, número de pares de folhas, área foliar e peso das porções aérea e radicular, bem como o peso total da planta; um outro grupo foi obtido por meio de medidas relativas de peso da planta, obtendo-se um percentual da parte aérea e radicular. A codificação dessas variáveis encontram-se na Tabela 1.

\section{RESULTADOS E DISCUSSÕES}

Todas as medidas foram influenciadas $(\mathrm{p}<0,01)$ pelo nível de sombreamento, à exceção das razões de biomassa da porção aérea e radicular e biomassa total da planta (Tabela, 2). De um modo geral, a variação dada pela razão de somas de quadrados, obtida pelo modelo adotado situou-se entre $55 \%$ e $87 \%$ de explicação da variação total (Tabela 2).

A ausência de efeito dos graus de sombreamento nas razões de biomassa das porções aérea [\%PSPA] e radicular [\%PSR], (Tabela 2) ressalta a estabilidade da espécie no que se refere à alocação energética durante o seu desenvolvimento. Assim, pode-se dizer que, independente da luminosidade, a planta do cafeeiro faz sua alocação de energia e produção de biomassa de forma semelhante. As funções estimadas assinalam um sombreamento médio (50\%) como o ponto de máxima para a alocação de biomassa

Ciênc. agrotec., Lavras. V.27, n.1, p.134-140, jan./fev., 2003 
na porção radicular e de mínima na porção aérea (Figura $1, \mathrm{~b}$ ).

Tais tendências mostram um comportamento característico de plantas de hábito umbrófilo. Pode-se dizer, com isso, que valores de sombreamento acima do médio $(50 \%)$ são indicados.
O número de pares de folhas [NPAR] e, conseqüentemente, a área foliar [AF], indicaram o sombreamento médio (50\%) como o de maior valor médio, ocorrendo menor valor médio na ausência de sombreamento (0\%), (Tabela 3). O modelo também indicou um efeito quadrático, tendo como ponto de máxima o grau médio de sombreamento (50\%) (Figura 2, b).

TABELA 1 - Características medidas no experimento de desenvolvimento de plantas jovens de café, descrição, codificação e unidades referentes.

\begin{tabular}{|c|c|c|c|}
\hline Natureza & Medidas & Código & Unidades \\
\hline \multirow{9}{*}{ Crescimento } & Altura da planta & {$[\mathrm{ALT}]$} & $\mathrm{cm}$ \\
\hline & Diâmetro da planta & [DIAM] & $\mathrm{mm}$ \\
\hline & $\mathrm{N}^{\circ}$ de pares de folhas & [NPAR $]$ & unid. \\
\hline & Peso da porção aérea & [PSPA] & $\mathrm{g}$ \\
\hline & Peso da porção radicular & {$[\mathrm{PSR}]$} & g \\
\hline & Peso total da planta & [PTOT] & g \\
\hline & Porção aérea (\%) & {$[\% \mathrm{PSPA}]$} & $\%$ \\
\hline & Porção radicular (\%) & {$[\% \mathrm{PSR}]$} & $\%$ \\
\hline & Área foliar & {$[\mathrm{AF}]$} & $\mathrm{cm}^{2}$ \\
\hline
\end{tabular}

TABELA 2 - Quadro de análise de variância para o efeito do sombreamento sobre as medidas crescimento. UFLA, Lavras - MG, 2001.

\begin{tabular}{ccccccc}
\hline \multirow{2}{*}{ Variáveis } & G.L. & \multicolumn{3}{c}{ QM } & \multirow{2}{*}{ F } & P \\
\cline { 3 - 4 } & & Efeito & Erro & & \\
\hline$[$ ALT] & $(3 ; 12)$ & 14,315 & 0,527 & 27,170 & $* *$ \\
{$[\mathrm{DIAM}]$} & $(3 ; 12)$ & 0,105 & 0,014 & 7,624 & $* *$ \\
{$[\mathrm{NPAR}]$} & $(3 ; 12)$ & 0,310 & 0,062 & 5,027 & $* *$ \\
{$[\mathrm{PSPA}]$} & $(3 ; 12)$ & 0,090 & 0,015 & 5,846 & $* *$ \\
{$[\mathrm{PSR}]$} & $(3 ; 12)$ & 0,003 & 0,001 & 4,990 & $* *$ \\
{$[\mathrm{PTOT}]$} & $(3 ; 12)$ & 0,129 & 0,022 & 5,919 & $*$ \\
{$[\% \mathrm{PSPA}]$} & $(3 ; 12)$ & 0,000 & 0,000 & 0,563 & n.s. \\
{$[\% \mathrm{PSR}]$} & $(3 ; 12)$ & 0,000 & 0,000 & 0,563 & n.s. \\
{$[\mathrm{AF}]$} & $(3 ; 12)$ & 3417,412 & 132,220 & 25,846 & $* *$ \\
\hline
\end{tabular}

Em que: n.s. - não significativo $(\mathbf{p} \geq \mathbf{0 , 0 5})$; ** - significativo $(\mathbf{p}<0,01)$. 
(a)

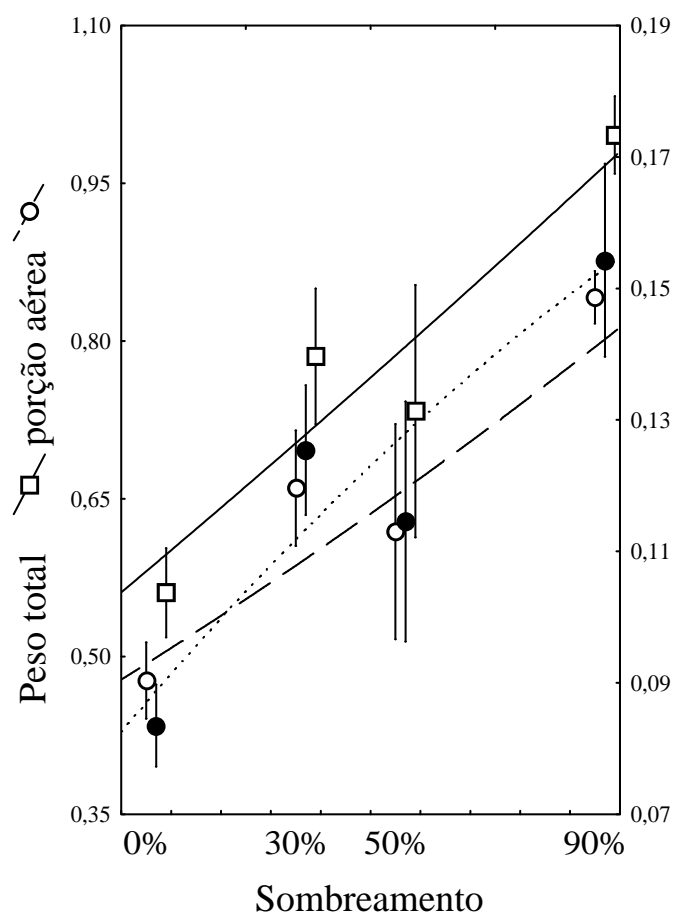

(b)

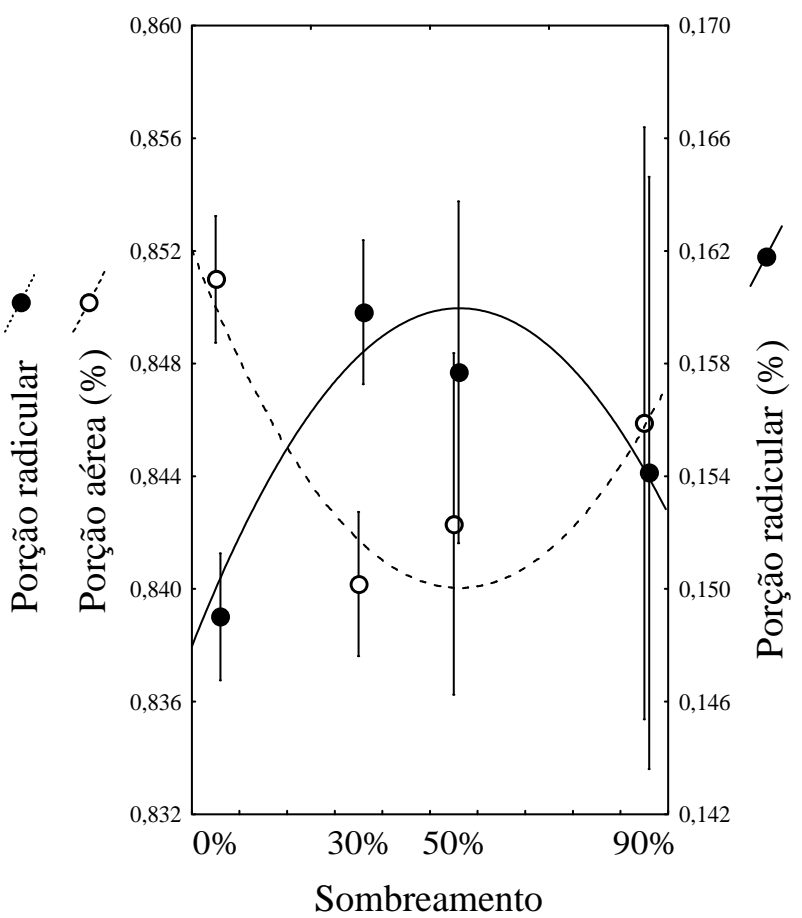

FIGURA 1 - Valores médios e intervalos de confiança de 95\%, ajustes obtidos para (a) biomassa total da planta e das porções aérea e radicular e (b) razão de biomassa das porções aérea e radicular e biomassa total da planta. UFLA, Lavras - MG, 2001.

A altura das plantas [ALT] apresentou maiores valores no sombreamento médio $(50 \%)$, com o mesmo padrão indicado para $[\mathrm{AF}]$ (Tabela 3 e Figura 2, a). Já o diâmetro da planta [DIAM] apresentou maiores valores no sombreamento máximo (90\%) (Tabela 3). O modelo ajustado mostra uma tendência crescente do diâmetro em função do aumento do grau de sombreamento, a partir do valor médio acima do sombreamento (Figura 2). A diferença entre os valores médios do grau máximo de sombreamento foi da ordem de $15 \%$ (Tabela 3 ).

Já a biomassa das plantas [PTOT], em qualquer uma das porções avaliadas [PSPA] e [PSR], apresentou maiores valores no maior grau de sombreamento (90\%), e os menores em pleno sol (0\%) (Tabela 3). Diferenças entre os valores de máximo $(90 \%)$ e mínimo $(0 \%)$ de sombreamento situaram-se acima de $75 \%$ (Tabela 3 ).

Pelos resultados, verifica-se que a condição de $50 \%$ de sombreamento favoreceu o desenvolvimento das mudas de cafeeiro, visto que nelas foram encontrados valores maiores de altura, número de pares de folhas e área foliar. Isso somente não foi observado, quanto ao diâmetro, possivelmente pelo fato de essas plantas apresentarem um peso seco de raíz, parte aérea e total maior, o que está relacionado provavelmente a um maior acúmulo de biomassa (reserva) e água. Tal acúmulo, na condição de $50 \%$ de luminosidade, pode ter sido alocado para as partes em desenvolvimento da planta e transformadas em uma maior altura, número de pares de folhas e área foliar. 
TABELA 3 - Valores médios de altura [ALT] e diâmetro da planta [DIAM], $\mathrm{n}^{\circ}$ de pares de folhas [NPAR], peso da porção aérea [PSPA], porção radicular [PSR] e total da planta [PTOT], porção aérea (\%) [\%PSPA], porção radicular (\%) [\%PSR] e área foliar [AF] em função dos tratamentos de irradiação solar ordenados pelo teste de Tukey $(\alpha=0,05)$. UFLA, Lavras - MG, 2001.

\begin{tabular}{|c|c|c|c|c|c|c|c|c|c|c|}
\hline Sombream. & [ALT] & & [DIAM] & & [NPAR] & & {$[\mathbf{A F}]$} & & [PTOT] & \\
\hline $0 \%$ & 5,78 & $\mathrm{~cd}$ & 2,28 & $\mathrm{~b}$ & 3,45 & $\mathrm{bc}$ & 58,48 & $\mathrm{~d}$ & 0,56 & $\mathrm{~d}$ \\
\hline $30 \%$ & 7,36 & bc & 2,32 & $\mathrm{~b}$ & 3,60 & $\mathrm{bc}$ & 91,26 & $\mathrm{bc}$ & 0,79 & bc \\
\hline $50 \%$ & 10,26 & $\mathrm{a}$ & 2,30 & $\mathrm{~b}$ & 3,75 & $\mathrm{a}$ & 129,81 & $\mathrm{a}$ & 0,73 & $\mathrm{bc}$ \\
\hline $90 \%$ & 7,06 & bcd & 2,62 & $\mathrm{a}$ & 3,10 & $\mathrm{~b}$ & 88,89 & $\mathrm{bc}$ & 1,00 & $\mathrm{a}$ \\
\hline Média Geral & 7,62 & & 2,38 & & 3,48 & & 92,11 & & 0,77 & \\
\hline $\mathrm{CV} \%$ & 9,03 & & 5,33 & & 6,57 & & 12,67 & & 15,43 & \\
\hline Sombream. & [PSPA] & & [PSR] & & [\%PSPA] & & [\%PSR] & & & \\
\hline $0 \%$ & 0,48 & $\mathrm{~d}$ & 0,08 & $\mathrm{~d}$ & 0,85 & $\mathrm{a}$ & 0,15 & $\mathrm{a}$ & & \\
\hline $30 \%$ & 0,66 & $\mathrm{bc}$ & 0,13 & $\mathrm{bc}$ & 0,84 & $\mathrm{a}$ & 0,16 & $\mathrm{a}$ & & \\
\hline $50 \%$ & 0,62 & bc & 0,11 & $\mathrm{bc}$ & 0,84 & $\mathrm{a}$ & 0,16 & $\mathrm{a}$ & & \\
\hline $90 \%$ & 0,84 & $\mathrm{a}$ & 0,15 & $\mathrm{a}$ & 0,85 & $\mathrm{a}$ & 0,15 & $\mathrm{a}$ & & \\
\hline Media Geral & 0,65 & & 0,12 & & 0,84 & & 0,16 & & & \\
\hline $\mathrm{CV} \%$ & 18,07 & & 22,41 & & 5,67 & & 4,38 & & & \\
\hline
\end{tabular}

Em que: Valores precedidos de mesma letra, não diferem no nível de 5\%, pelo teste de Tukey.

(a)

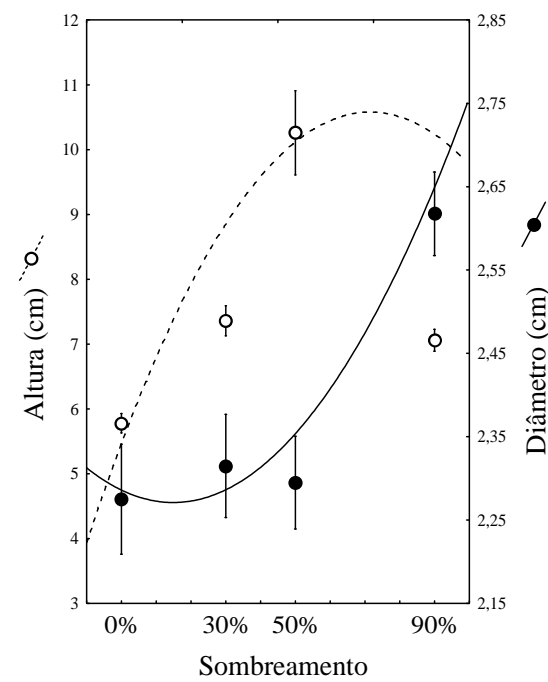

(b)

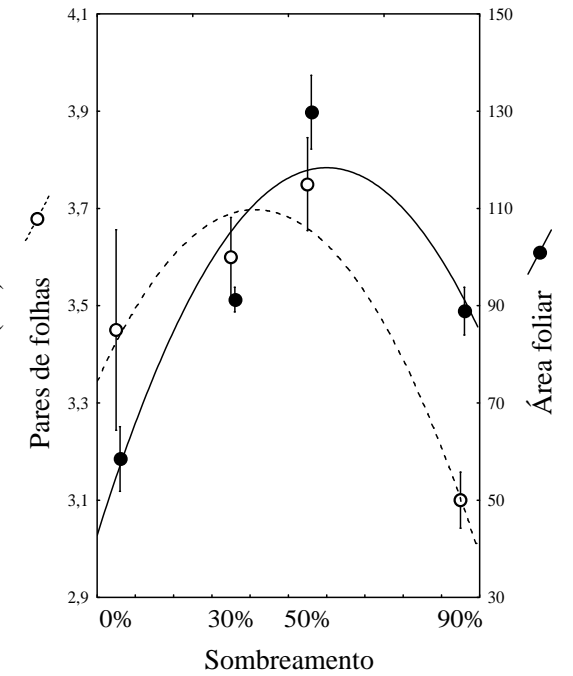

FIGURA 2 - v alores meuıus e miltervaıus ue comlança ue yj\%o e ajustes vouuus para (a) alıura e uiâmetro da planta e (b) número de pares de folhas e área foliar. UFLA, Lavras - MG, 2001. 


\section{CONCLUSÕES}

Pelos resultados apresentados, pode-se concluir que o melhor tipo de sombreamento para formação de mudas de cafeeiro é o de $50 \%$, pois nessas condições as plantas apresentam um maior crescimento vegetativo em relação aos demais sombreamentos e às mudas formadas a pleno sol.

\section{REFERÊNCIAS BIBLIOGRÁFICAS}

BOARDMAN, N. K. Comparative phothosynthesis of sun and shade plants. Annual Review of Plant Physiology, California, v. 28, p. 355-377, 1977.

ENGEL, V. L. Influência do sombreamento sobre o crescimento de mudas de essências nativas, concentração de clorofila nas folhas e aspectos de anatomia.
1989. 202 p. Dissertação ( Mestrado em Ciências Florestais) - Escola Superior de Agricultura "Luiz de Queiróz, Piracicaba.

FERREIRA, M. das G. R. Efeito do sombreamento na produção de mudas de quatro espécies florestais nativas. 1977. 42 p. Dissertação - (Mestrado em Ciências Florestais) - Universidade Federal de Viçosa, Viçosa.

MATIELLO, J. B.; BARROS, U. V.; BARBOSA, C. M.; ARAÚJO, P.; VIDIGAL, J. E. Viveiro de mudas a pleno Sol na Zona da Mata de Minas gerais. In: CONGRESSO DE PESQUISAS CAFEEIRAS, 23., 1997, Curitiba. Anais... Manhuaçu: [s.n.], 1997. p. 47. 